US Army Corps

of Engineers ${ }_{\circledast}$

Engineer Research and

Development Center

\title{
Estimation of 2D Clutter Maps in Complex Under-Canopy Environments from Airborne Discrete-Return Lidar
}

Heezin Lee, Michael J. Starek, S. Bruce Blundell,

December 2019

Michael Schwind, Christopher Gard, and Harry Puffenberger 
The U.S. Army Engineer Research and Development Center (ERDC) solves the nation's toughest engineering and environmental challenges. ERDC develops innovative solutions in civil and military engineering, geospatial sciences, water resources, and environmental sciences for the Army, the Department of Defense, civilian agencies, and our nation's public good. Find out more at www.erdc.usace.army.mil.

To search for other technical reports published by ERDC, visit the ERDC online library at http://acwc.sdp.sirsi.net/client/default. 


\section{Estimation of 2D Clutter Maps in Complex Under-Canopy Environments from Airborne Discrete-Return Lidar}

S. Bruce Blundell, Christopher Gard, and Harry Puffenberger

U.S. Army Engineer Research and Development Center

Geospatial Research Laboratory

7701 Telegraph Road

Alexandria, VA 22315

Heezin Lee

National Center for Airborne Laser Mapping

Department of Earth and Planetary Science

University of California at Berkeley

Berkeley, CA 94720

Michael J. Starek and Michael Schwind

School of Engineering and Computing Sciences

Texas A\&M University - Corpus Christi

Corpus Christi, TX 78412

Final report

Approved for public release; distribution is unlimited.

Prepared for U.S. Army Corps of Engineers

Washington, DC 20314-1000

Under GATE/ULM 11L025 


\section{Abstract}

Detection of near-ground objects occluded by above-ground vegetation from airborne lidar measurements remains challenging. Our hypothesis is that the probability of obstruction due to objects above ground at any location in the forest environment can be reasonably characterized solely from airborne lidar data. The essence of our approach is to develop a datadriven learning scheme that creates high-resolution 2D probability maps for obstruction in the under-canopy environment. These maps contain information about the probabilities of obstruction (clutter map) and lidar undersampling (uncertainty map) in the near-ground space. Airborne and terrestrial lidar data and field survey data collected within the forested, mountainous environment of Shenandoah National Park, Virginia USA are utilized to test and evaluate the proposed approach in this work. A newly developed individual tree detection algorithm is implemented to estimate undersampled stem contributions to the probability of obstruction. Results show the effectiveness of the tree detection algorithm with an accuracy index of between $61.5 \%$ and $80.7 \%$ (tested using field surveys). The estimated clutter maps are compared to the maps created from terrestrial scans (i.e., ground truth) and the results show the root-meansquare error of $0.28,0.32$, and 0.34 at three study sites. The overall framework in deriving near-ground clutter and uncertainty maps from airborne lidar data would be useful information for prediction of line-ofsight visibility, mobility and above-ground forest biomass.

DISCLAIMER: The contents of this report are not to be used for advertising, publication, or promotional purposes. Citation of trade names does not constitute an official endorsement or approval of the use of such commercial products. All product names and trademarks cited are the property of their respective owners. The findings of this report are not to be construed as an official Department of the Army position unless so designated by other authorized documents. 


\section{Contents}

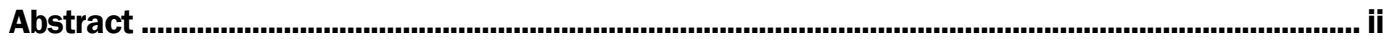

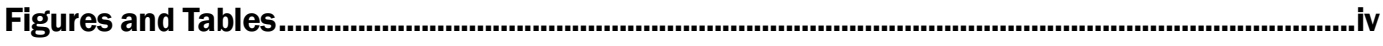

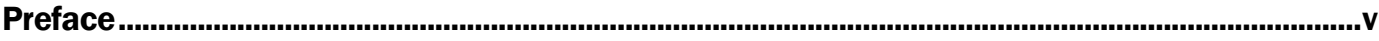

1 Introduction ................................................................................................................................. 1

2 Study Area and Datasets .......................................................................................................... 4

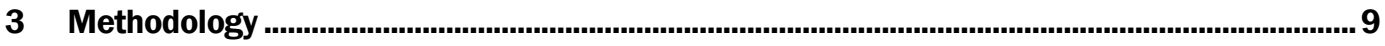

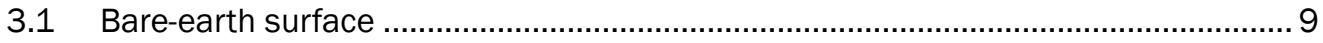

3.2 Individual tree segmentation ...................................................................... 10

3.3 Understory objects........................................................................................ 13

3.4 Clutter maps ............................................................................................. 14

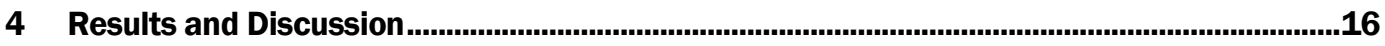

5 Conclusions ............................................................................................................................23

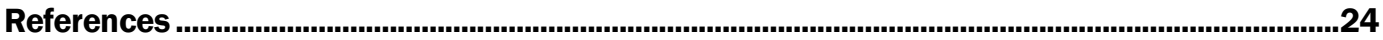

Report Documentation Page 


\section{Figures and Tables}

\section{Figures}

Figure 1. Flow diagram of the proposed methodology addressing key components, starting from the airborne lidar data to the creation of a clutter map.

Figure 2. Study sites. The location of the Shenandoah National Park, VA (a) and the locations of three study sites inside the area (b). The airborne lidar coverages enclosing each study site are shown with red squares $(1 \mathrm{~km} \times 1 \mathrm{~km})$ on Google Maps. Top views of the $50 \mathrm{~m} * 50 \mathrm{~m}$ selected study areas of analysis centered at the field survey location for the site of Hazel (c), Numbers (d), and Georgie (e). Field surveyed tree locations are shown as black circles on airborne lidar points color-coded by elevation

Figure 3. (a) Photo from a co-aligned digital camera in the terrestrial lidar scanner illustrating a scene at site Georgie; (b) Example of terrestrial lidar point cloud textured by the camera RGB values showing a slightly zoomed in portion of the same scene. The blue line in (a) represents the horizon as an artifact of the mosaicking process. Ovals show examples of features that appear in both the digital image and terrestrial scan, visually showing the level of detail in the scanning process.

Figure 4. Flowchart of the proposed tree segmentation algorithm. Input point set $A$ is the whole lidar dataset. $A^{\prime}$ is a subset of $A$ representing the set of points excluding those from the upper story trees. The parameters used in each step are marked; in finding treetops, $R$ is the search radius, $R_{\max }$ and $R_{\min }$ are the maximum and minimum search radius respectively, and $\Delta$ is the step size of $R$. In the region growing step, $T$ is a gradually increasing interval to associate lidar point with the treetops.

Figure 5. Detected treetop locations on airborne lidar points color-coded by elevation at (a) Hazel, (b) Numbers, and (c) Georgie site (circular area with diameter of $50 \mathrm{~m}$ each). All detected trees are represented as blue circles.

Figure 6. 2D clutter maps (circular area with diameter of $40 \mathrm{~m}$ each) estimated from the airborne lidar data computed for the areas of overlap with the terrestrial lidar surveys, showing the probability of obstruction over the study site (a) Hazel, (b) Numbers, and (c) Georgie. Terrestrial lidar data is used to create the ground truth clutter maps for (d) Hazel, (e) Numbers, and (f) Georgie. Lighter color represents higher possibility of obstruction and darker color represents less obstruction at the specific location. (map resolution $=0.5 \mathrm{~m}$ )

Figure 7. Result maps at the site of Numbers. (a) A clutter map showing the probability of obstruction, $P(O \mid X, Y)$, over the area of interest (circular area with diameter of $40 \mathrm{~m})(\mathrm{b}) \mathrm{A}$ map showing the probability of uncertainty, $P(U \mid X, Y)$, in the understory space. (c) A 2D united map showing the probabilities of both clutter and uncertainty. The uncertainty is in color scale: more bluish color for less uncertainty and more redish color for more uncetainty. The clutter information is shown as a shaded relief image to produce an appearance of 3D space with lighting from the upper-left corner of the map. The more visually apparent relief indicates higher probability of clutter. (map resolution $=0.5 \mathrm{~m}$ )

\section{Tables}

Table 1. General information about the sites from the field survey. ................................................. 5

Table 2. Parameters and their configurations used in this study......................................................16

Table 3. Accuracy measures of the individual tree detection results for the study sites ..................19 


\section{Preface}

This study was originally conducted for the Geospatial Research Laboratory under project 11L025, "GATE/ULM" (completed FY17). The technical monitor was Mr. Nathan Frantz.

The project was executed by the Data and Signature Analysis Branch (TRS) of the TIG Research Division (TR), Army Engineer Research and Development Center, Geospatial Research Laboratory (ERDC-GRL). At the time of publication of this Miscellaneous Paper, Ms. Jennifer L. Smith was Chief, Data Signature and Analysis Branch (CEERD-TRS); Ms. Martha Kiene was Chief, TIG Research Division (CEERD-TR); and Mr. Ritchie Rodebaugh was Director of the Technical Directorate (CEERD-TET). The Deputy Director of ERDC-GRL was Ms. Valerie L. Carney and the Director was Mr. Gary Blohm.

COL Teresa A. Schlosser was Commander of ERDC, and Dr. David W. Pittman was the Director.

The authors are grateful to the U.S. Army Engineer Research and Development Center (ERDC) Geospatial Research Laboratory (GRL) for providing the airborne and terrestrial lidar observations and field survey data. This research was supported by the U.S. Army ERDC-GRL under the grant W9132V-14-C-0003. 


\section{Introduction}

Because of its ability to generate precise three-dimensional information about the surface of the Earth, airborne lidar (light detection and ranging) sensors have been increasingly used for diverse terrain-based applications such as urban modeling (Lu et al. 2011; Awrangjeb and Fraser, 2014), discovery of archaeological features (Fernandez-Diaz et al. 2014; Hare et al. 2014), and geological feature analysis (Oskin et al. 2012; Booth et al. 2013; Zielke et al. 2015). Because of lidar's ability to record multiple returns per an emitted laser pulse and penetrate through vegetation, it has been also widely used for forestry applications: creating digital elevation models (DEMs) within forested terrain (Vosselman and Maas, 2010; Wilson, 2012; Vega et al. 2012) and in the estimation of forestry metrics (Maltamo et al. 2014; Lefsky et al. 2002). Lidar point cloud data provides a $3 \mathrm{D}$ representation of the vertical forest structure enabling identification of individual trees (Lee et al. 2010; Jakubowski et al. 2013; Strimbu and Strimbu, 2015; Khosravipour et al. 2015) and extracting tree canopy parameters (Chen et al. 2007; Palminteri et al. 2012). Lidar has also been used to find voids inside forests to estimate microwave signal attenuation (Liu et al. 2011; Wright et al. 2008), intercepted photosynthetically active radiation (Lee et al. 2009), and within-canopy line-of-sight visibilities (Lee et al. 2013).

Measuring near-ground vegetation structure under the forest canopy is important for forest research and a variety of other problems including line-of-sight visibility and mobility estimation. However, imaging the understory structure by overhead sensors has been an extremely challenging task, especially in areas covered with dense vegetation. Even with recent advances in airborne lidar technologies and algorithms, accurate characterization of understory vegetation and visibility occlusion remains a challenging problem due to lidar undersampling of the vertical structure within this layer. Tree stems (trunks) have been of major interest in forest measurement because of their close relationship to timber production and biomass, and they are also significant elements in blocking vision and impeding movement. However, unfortunately, tree stems are usually the least sampled, and consequently, the most difficult objects to detect by airborne lidar (Bucksch et al. 2014). 
This study constructs a methodology to develop probabilistic maps of clutter (i.e., visibility/mobility occlusion) within forested environments by accounting for the topography, understory vegetation and near-ground objects, and tree stem contributions using airborne discrete-return lidar. The methodology developed here is generalizable such that any bare-earth extraction method and tree segmentation algorithm could be implemented to replace the proposed approaches within the workflow. The performance of estimating near-ground obstruction is also characterized with respect to the lidar sampling characteristics (or canopy density). The resultant framework and occlusion maps are expected to serve as valuable input to $3 \mathrm{D}$ forest modeling and tactical operations.

The framework addresses four key components (as shown in Figure 1):

1. model the contribution of the underlying topographic surface for detection of near ground lidar returns;

2. develop an improved segmentation algorithm to detect individual trees and estimate the impact of tree stems and foliage contribution;

3. characterize the contribution of understory objects, such as boulders, bushes and small trees given the undersampling inherent in below-canopy lidar data; and

4. produce high-resolution maps showing near-ground terrain features in a probabilistic manner by combining the outputs from components 1-3. 
Figure 1. Flow diagram of the proposed methodology addressing key components, starting from the airborne lidar data to the creation of a clutter map.

\section{Methodology Overview}

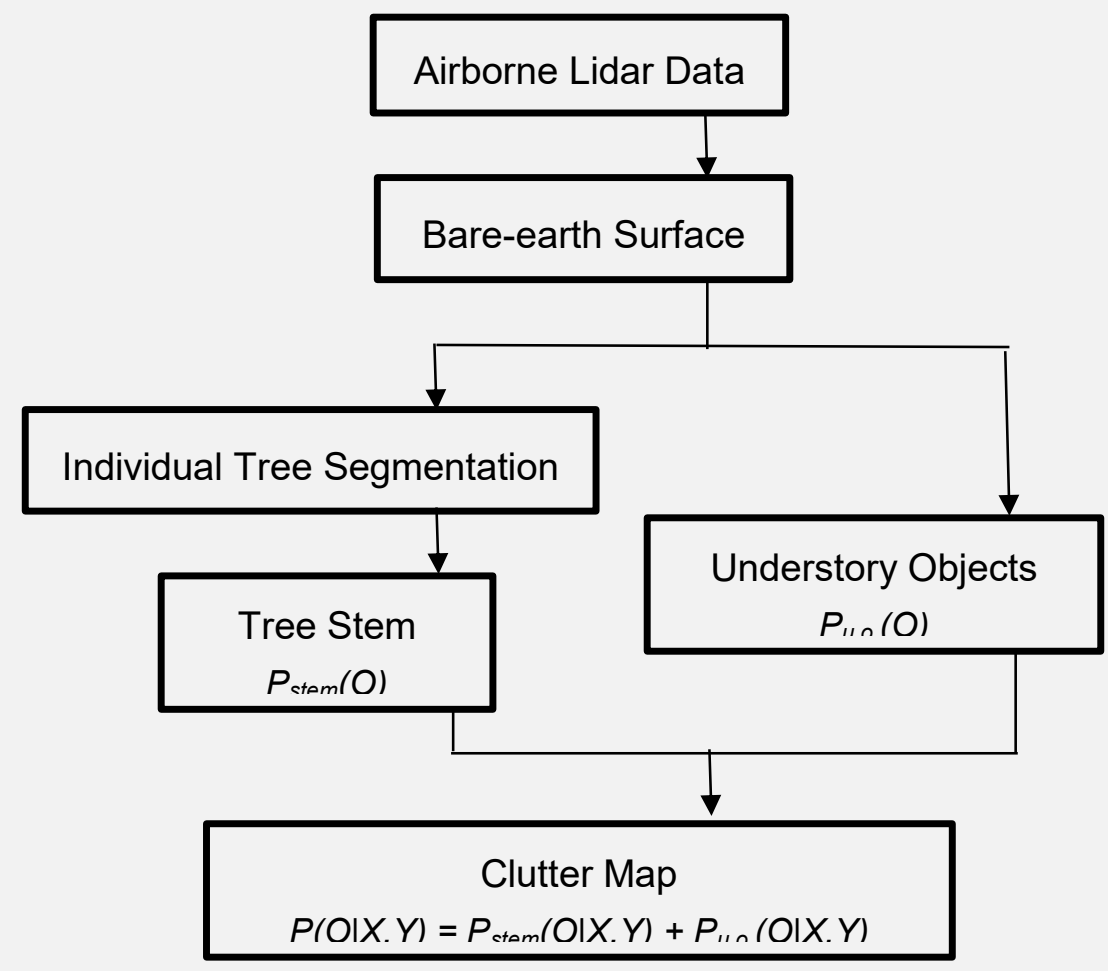




\section{Study Area and Datasets}

The primary objective of this study is to develop a scalable model for deriving spatially detailed, near-ground terrain clutter maps within forested environments through exploitation of the vertical structure information captured by airborne lidar point cloud data. To attain this end, we analyzed data from airborne and terrestrial lidar surveys and in situ field surveys conducted in the Shenandoah National Park, Virginia USA. Three study sites within the forested, mountainous environment were selected with varying topography (rocky, hilly, and valley) and canopy cover at each site providing a range of terrain-canopy interactions to test the proposed idea. Images of the study sites are shown in Figure 2. The site of "Hazel" is located in a valley and it has relatively open vegetation cover with higher profile trees (pignut hickory as a dominant species) (see Table 1). The site of "Numbers" is located on the top of a hill and the vegetation coverage is more closed and the stem density is higher with lower profile dominant trees; $80 \%$ of the trees are chestnut oaks. The last site "Georgie" is located very close to an open, rocky area but it has similarly closed canopy cover to Numbers with a different mix of tree species. The trees in this site are stressed due to thin soils and high winds. 
Figure 2. Study sites. The location of the Shenandoah National Park, VA (a) and the locations of three study sites inside the area (b). The airborne lidar coverages enclosing each study site are shown with red squares $(1 \mathrm{~km} \times 1 \mathrm{~km})$ on Google Maps. Top views of the $50 \mathrm{~m} * 50 \mathrm{~m}$ selected study areas of analysis centered at the field survey location for the site of Hazel (c), Numbers (d), and Georgie (e). Field surveyed tree locations are shown as black circles on airborne lidar points color-coded by elevation.

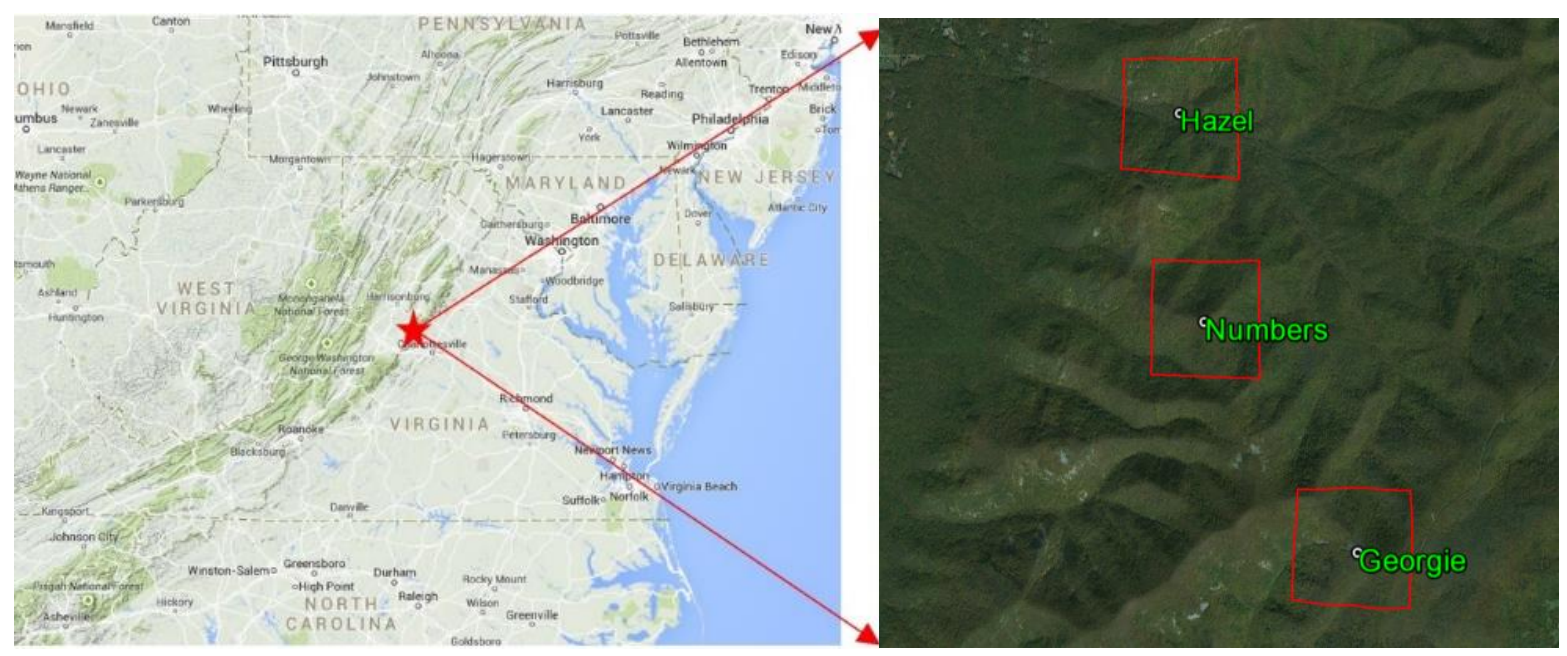

(a)

(b)

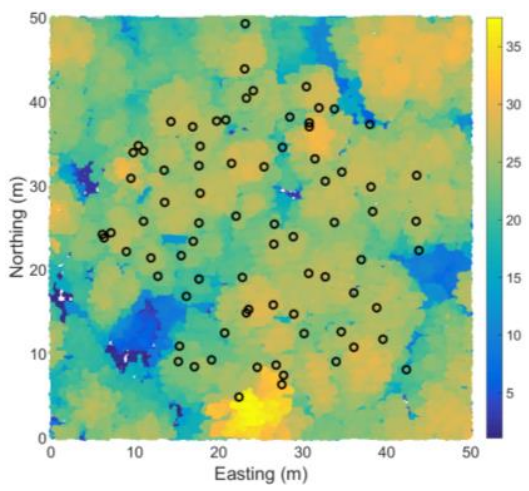

(c)

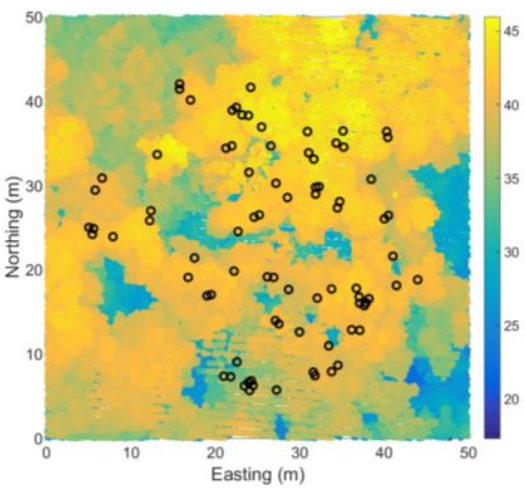

(d)

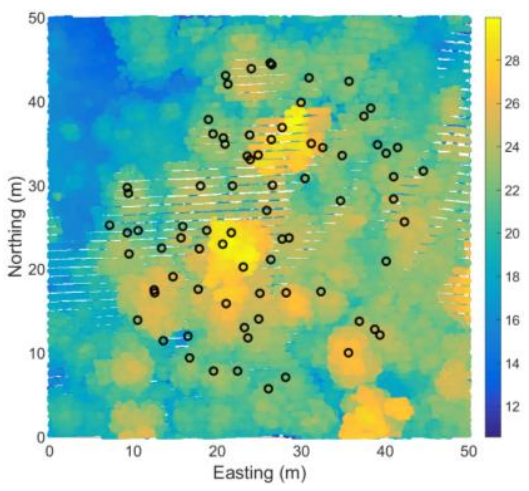

(e)

Table 1. General information about the sites from the field survey.

\begin{tabular}{|l|l|l|l|l|l|}
\hline Site & $\begin{array}{l}\text { Number } \\
\text { of Trees }\end{array}$ & $\begin{array}{l}\text { Highest Frequency } \\
\text { Tree Species } \\
\text { (counts) }\end{array}$ & $\begin{array}{l}\text { Average } \\
\text { DBH (cm) }\end{array}$ & $\begin{array}{l}\text { Average Tree } \\
\text { Height }(\mathrm{m})\end{array}$ & $\begin{array}{l}\text { Average Crown } \\
\text { Width (m) } \\
\text { (major, minor) }\end{array}$ \\
\hline Hazel & 78 & Pignut Hickory (30) & 22.99 & 17.26 & $8.19,8.64$ \\
\hline Numbers & 93 & Chestnut Oak (73) & 23.37 & 11.18 & $6.68,6.79$ \\
\hline Georgie & 83 & Black Birch (39) & 16.09 & 8.29 & $6.35,6.76$ \\
\hline
\end{tabular}


Discrete-return airborne lidar point cloud data (up to five returns per pulse) were collected by a Leica Geosystems ALS70 scanner in August 2012, and the lidar point density was 27.8, 31.9, and 29.6 points per square meter for Hazel, Numbers and Georgie, respectively. The terrestrial lidar survey was performed in March and May 2012 with a Leica ScanStation C10 scanning from five positions for each plot area to create dense 3D maps as shown in Figure 3. There were one scan in the plot center and four scans around the periphery with the distance from the plot center scan ranging from $13 \mathrm{~m}$ to $23 \mathrm{~m}$. The objective was to acquire data with no major gaps in coverage due to stem occlusion while ensuring we meet an average sampling density of more than one point per square centimeter; the average point density was $2.88,5.51$, and 4.75 points per square centimeter for Hazel, Numbers and Georgie, respectively. The field survey of tree parameters was performed in April 2012 and served as ground truth data sets. Each study site is a circle of $20 \mathrm{~m}$ radius, and the diameter at breast height $(D b h)$ for each tree stem over $10 \mathrm{~cm}$ in diameter was measured. Basic statistics of the tree parameters, number of trees and highest frequency tree species are shown in Table 1. Tree height and $D b h$ were measured for all trees, and crown widths in two orthogonal directions were estimated for each dominant and co-dominant tree (those with higher relative canopy positions) using hypsometric techniques. The study sites have various tree species; Hazel has 13, Numbers has 8, and Georgie has 9 different tree species inside the study area.

Figure 3. (a) Photo from a co-aligned digital camera in the terrestrial lidar scanner illustrating a scene at site Georgie; (b) Example of terrestrial lidar point cloud textured by the camera RGB values showing a slightly zoomed in portion of the same scene. The blue line in (a) represents the horizon as an artifact of the mosaicking process. Ovals show examples of features that appear in both the digital image and terrestrial scan, visually showing the level of detail in the scanning process.

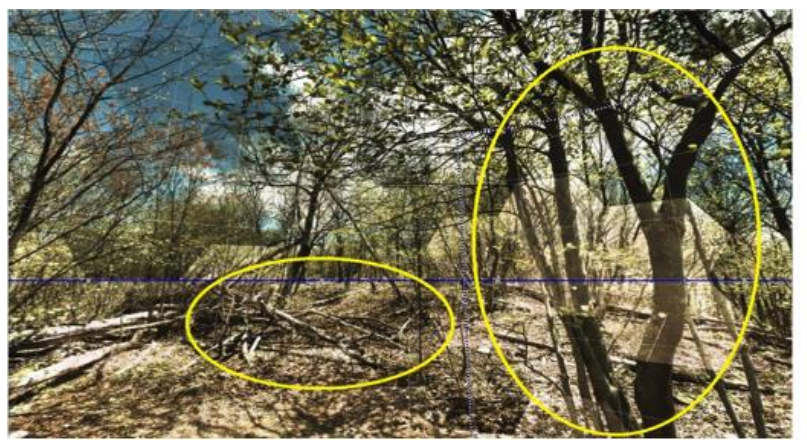

(a)

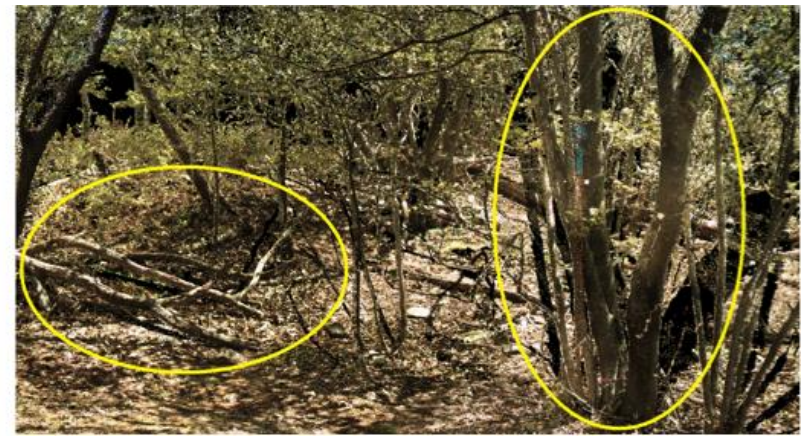

(b) 
The terrestrial lidar data serves as a "ground truth" model of the $3 \mathrm{D}$ structure of the forested terrain for evaluating performance of the developed clutter estimation method outlined in the sections below. Coregistration of the airborne and terrestrial lidar data was necessary to improve alignment between the data sets. Although both data sets were spatially referenced relative to the same datum and projection, a positive vertical bias of approximately $0.59 \mathrm{~m}$ was observed in the airborne lidar data relative to the terrestrial lidar data with a horizontal shift up to $0.8 \mathrm{~m}$, generally in the south and east direction. In contrast, the in situ field survey data of stem locations compared to their locations measured in the terrestrial lidar point cloud aligned very closely. Due to the natural, complex geometry of the forested and mountainous environment and differences in point cloud density, standard point-to-point geometric feature matching (e.g., linear features like building edges [Habib et al. 2005; Yang et al. 2015]) and transformation was not suitable.

Long occupation static GPS was used to set benchmarks in open forested regions near each study site that were not subjected to multipathing and constellation view occlusion. Total stations were then used to transect into the forest and georeference tree stem measurements acquired during the field survey as well as georeference targets used for registration of the terrestrial lidar scans. The terrestrial lidar survey data and field survey data closely aligned and were considered to be of higher order accuracy compared to the airborne lidar data. A commercial data provider collected the airborne lidar data and details on the calibration process implemented were not available. Initially, it was thought that the observed offsets may stem from a difference in datum specifications between the airborne and ground data (i.e., improper metadata). After examining the effects of datum shifts for candidate suspects, this was determined not to be the cause. Therefore, it is suspected that at least a portion of the observed vertical bias may stem from longer period GPS error induced in the aircraft trajectory that may not have been removed (e.g., vertical shifting relative to RTK GPS road profiles). Additional sources of error include poorly calibrated biases in the bore-sighting parameters relating the system components as well as biases in the system measurements (e.g., ranges and mirror angles). Over highly sloped terrain planimetric errors can amplify vertical error leading to further accuracy degradation.

To register the airborne lidar data set to the terrestrial scans a two-stage approach was implemented. Firstly, the upper level of the canopy as 
represented by the terrestrial lidar point cloud and airborne lidar point cloud was segmented. The upper canopy had the densest representation by the airborne scan and provided the most identifiable $3 \mathrm{D}$ structure features (tree tops) between the two data sets. A variant of the iterative closest point (ICP) algorithm was then implemented on the segmented clouds to determine the optimal transformation parameters (translation and rotation) for registration of the airborne point cloud with the terrestrial lidar point cloud (Besl and McKay, 1992; Henning and Radtke, 2006; nissen et al. 2012). Although translation was significant, rotation offset was minor with only a slight heading correction (rotation about the z-axis) applied. This transformation served to align the scans horizontally. Secondly, a residual vertical offset was then determined by differencing bare-earth digital elevation models (DEMs) derived from the transformed airborne point cloud and the terrestrial point cloud (see Section III for DEM details). The mean elevation offset computed within the area of overlap was then subtracted from the transformed airborne cloud to provide a final vertical correction. Due to slight differences in misalignment between study sites, the aforementioned registration approach was applied individually to each study site. This enabled close alignment between scans for algorithm performance evaluation. 


\section{Methodology}

\subsection{Bare-earth surface}

Modeling of the bare-earth surface using discrete-return airborne lidar data first commences by classifying the point set into ground and nonground points (Lu et al. 2009; Polat and Uysal, 2015). In this study, the last return airborne lidar data were filtered to remove non-ground points using a Triangular Irregular Network (TIN) densification algorithm implemented within the software LASTools (Isenburg, 2015). The ground point filter works by generating a sparse TIN from neighborhood minima (set of points with local lowest elevation) and then progressively adds points based on certain criteria in relation to the triangle that contains the candidate (Axelsson, 2000). The filter has several parameters that can be adjusted to impact filter performance.

These parameters include the step size, which governs size of objects removed; a larger step size (e.g., > 5 meter) implies larger objects could exist in the scene, such as buildings, and as such a smaller step size is more appropriate for natural terrain and forested landscapes. The spike parameter determines the threshold at which spikes during the TIN generation process get removed. The offset parameter determines the maximal offset up to which points above the current ground estimate get included. The search space is used to intensify the search space for initial ground points and is useful in highly varying and vegetated terrain as is the case here (Isenburg, 2015).

In this study, a parameter setting was chosen (5 m step, extra-fine search) that provided adequate surface detail while minimizing the incorporation of near ground occluding objects like boulders and short vegetation (see Table 2). The process for determination of these parameters is described in Section IV below. The classified ground point set was then used to generate a $1 \mathrm{~m}$ bare-earth DEM using regularized spline under tension interpolation with cross-validation (Mitášová and Mitáš, 1993; Mitášová et al. 2005; Hofierka et al. 2007). The result is a smoothed DEM surface representation of the underlying contiguous topography. 


\subsection{Individual tree segmentation}

To overcome the lidar undersampling of the understory in forests, physical knowledge of trees is acquired by segmenting individual trees. Isolating individual trees allows us to estimate essential tree parameters, such as tree height and crown dimension, which will associate the crowns with their corresponding stems. A recent study that compared eight different single tree detection algorithms in Alpine regions (Eysn et al. 2015) showed that a method based on local maxima detection within a rasterized canopy height model using variable-sized moving windows performed better in general, but this approach was inferior in complex multi-layered forests. A point cloud clustering-based method showed better performance in detecting trees in subdominant layers. The agglomerative clustering method (Lee et al. 2010) developed by one of us (Lee) was a combination of those two approaches to maximize the detection accuracy. That method showed its success (near 90\% detection accuracy) in identifying individual trees in managed pine forests, but that algorithm was specifically designed for single-layered forests. In this study, an advanced approach evolved from the method in (Lee et al. 2010) is developed to be applicable for detecting both upper-story and mid/understory trees in multi-layered complex forests.

As the beginning step, the algorithm attempts to identify the treetop for each tree crown in the lidar point clouds. Finding treetop points is a difficult task because of varying sizes and irregular shapes of tree crowns. It is also the most crucial step because the result severely affects the following steps. Similar to the window size of a local maximum filter, we use the search radius, $R$, to determine the minimum required tree crown radius, and the treetop point is assumed to be the highest lidar point for a particular tree crown. Given the size of $R$, the treetops are identified by repeated steps; (1) finding the highest point in the whole data set (this is the first treetop found), (2) reducing the search set by removing points within the circular search region $S$ with the radius of $R$, centered at the point found in the previous step, (3) finding the next highest point in the new search set acquired from (2), and accepting this point as a treetop if it is higher than any points inside $S$, (4) repeating the steps of (2) and (3) until the lidar points are exhausted.

Determining the size of $R$ is another challenging problem (as demonstrated in Lee et al. 2010) because, in general, $R$ has to vary to adapt to all different sizes of trees. In this study, we develop a top-down approach in applying the 
size of $R$; we start from the biggest size of $R, R_{\max }$, and iteratively reduce the size of $R$ until it reaches the smallest size of $R, R \min$. In the range of the search radius $R$, [ $\left.R_{\max }, R_{\min }\right]$, the size of the interval (or step size), $\Delta$, has to be decided. A small step size (e.g., $0.1 \mathrm{~m}$ ) would require many iterations resulting in high computational cost, so it would be desirable to use as large a step size as possible. More details on the process used to determine the parameters for this study is provided in Section IV.

By gradually reducing the size of $R$, we get more newly added treetops, and our confidence level on these new treetops goes down. To decide if a newly found treetop is true or a false positive, we now apply spin image representation, successfully used in shape matching and $3 \mathrm{D}$ object retrieval (Johnson and Hebert, 1999), to check the top-left to bottom-right diagonal signatures that result from the spin image process for actual trees (Lee, 2008). A spin image is created by mapping any point on the surface of the object in the $3 \mathrm{D}$ space onto a 2D space by defining two cylindrical coordinates, alpha and beta. The radial coordinate, alpha, is defined as the perpendicular distance to a line along the surface normal vector for an oriented point, and the elevation coordinate, beta, is defined as the perpendicular distance to the tangent plane defined by the vertex normal. Thus, (alpha, beta) coordinates provide a $2 \mathrm{D}$ index of a point relative to the oriented point. Instead of using fixed alpha and beta ranges in spin image computation, the ranges are acquired by a region growing algorithm (explained in the following paragraphs) on each treetop point. At each iteration with a decreasing $R$, we keep the seeds which are identified as real treetops and remove the others. By repeating this process until we reach $R_{\min }$, we acquire a complete set of real treetops, and this set represents the dominant and co-dominant trees in the area.

After finding treetop points, at each iteration, a region growing process is applied to associate the lidar points with the treetops. A set of lidar points grouped by this process represents an individual tree crown when the seed is a real treetop. The region growing process developed in (Lee et al. 2010) showed its success in a single level forest structure, but to apply to multilevel forest structures, we consider the $3 \mathrm{D}$ distance (rather than the $2 \mathrm{D}$ horizontal distance). By taking the elevation (i.e., Z-axis) into account in searching associated points, we could differentiate the trees separated in the $\mathrm{Z}$ direction (but overlapped in $\mathrm{X}-\mathrm{Y}$ space). This modification leaves a chance to identify and segment mid- and understory trees. 
To associate points with the treetops, we start from the highest lidar point (which is not in the set of treetop points) and find the nearest treetop point that is above the current considered point. If the distance between the current point and the seed point is smaller than an interval $T$, the current point is assigned the same index as the treetop. The interval $T$ is selected as small at the beginning and increased once all the lidar points in the region of interest are considered. The process is repeated until $T$ reaches $2 \mathrm{~m}$, so points which are further apart from others are not associated or indexed.

After segmenting the dominant and co-dominant trees from the above steps, their associated lidar points are excluded to create a new set of lidar points for searching mid/understory trees in multi-layered complex forests. For this new search, first, a simple ad hoc clustering algorithm is executed to cluster points in the new set; from the highest point, we simply keep adding neighboring points (less than $1 \mathrm{~m}$ apart from the current point or already grouped points) until no more neighboring points are in the vicinity, and repeat this process by selecting the next highest point in the remaining point set. Next, the spin image algorithm is run on each cluster to check the existence of a tree feature. If the number of lidar points in the cluster is not sufficient to compute a spin image, then we consider that this group of points is random noise, not providing enough information to decide the existence of a tree. Hence, only a cluster of lidar points which shows a distinct tree feature in a spin image (here, diagonal spread) is detected and classified as a tree. For a cluster to be qualified for the spin image test, the minimum number of points was set to 30 . In summary, a block diagram of the proposed algorithm is shown in Figure 4. 
Figure 4. Flowchart of the proposed tree segmentation algorithm. Input point set $A$ is the whole lidar dataset. $A^{\prime}$ is a subset of $A$ representing the set of points excluding those from the upper story trees. The parameters used in each step are marked; in finding treetops, $R$ is the search radius,

$R_{\max }$ and $R_{\min }$ are the maximum and minimum search radius respectively, and $\Delta$ is the step size of $R$. In the region growing step, $T$ is a gradually increasing interval to associate lidar point with the treetops.

Algorithm Flowchart
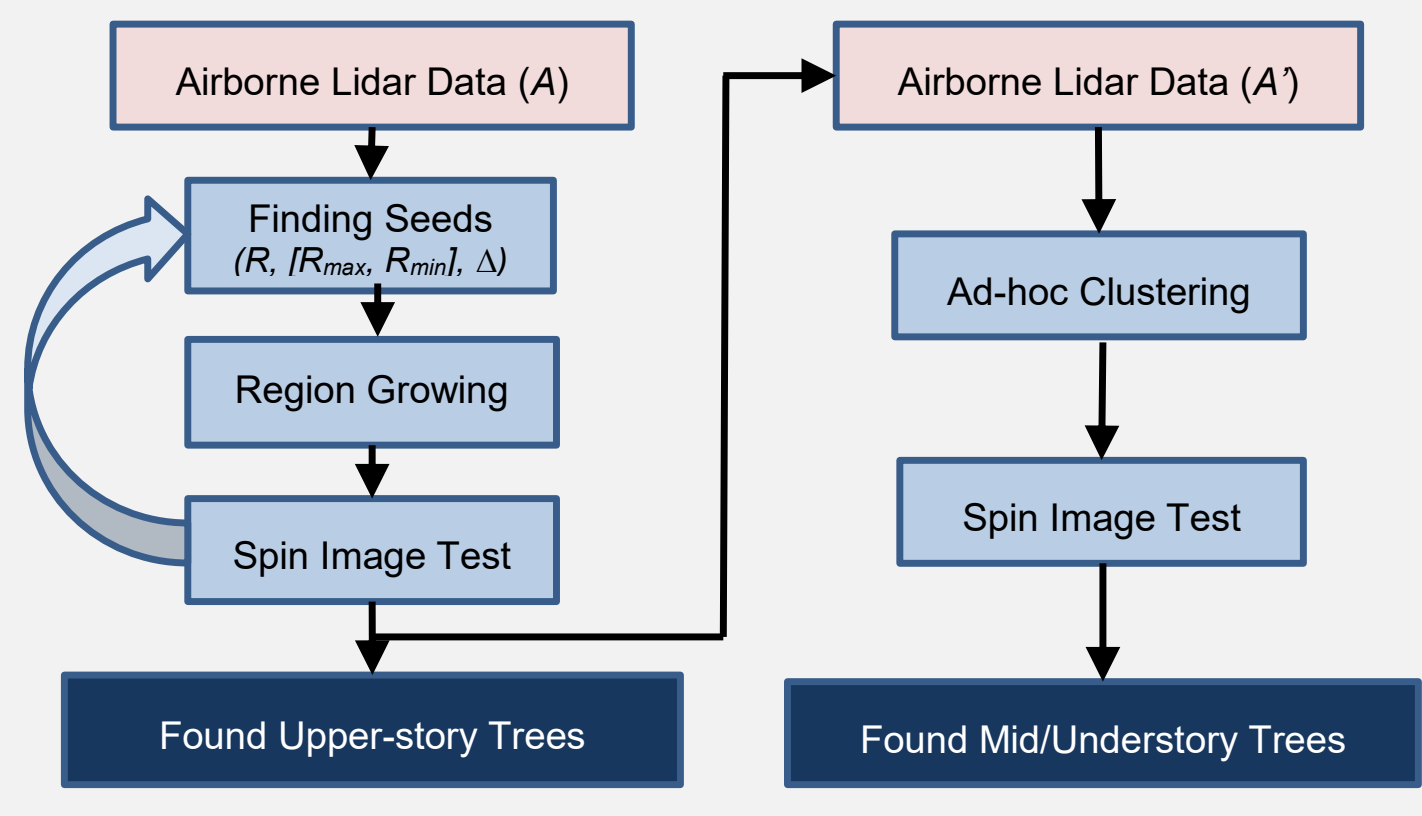

\subsection{Understory objects}

Tree stem contributions to the probability of occlusion, $P(O)$, are primary elements in this research, so it is required to estimate two major parameters: stem location $\left(S_{x y}\right)$ and diameter at breast height $(D b h)$. To do so, we employed a known allometric equation, $D b h=-0.16+C D+1.22 \times$ $T H$, developed in (Popescu, 2007), that related our lidar-estimated parameters of tree height $(T H)$ and crown diameter $(C D)$ to $D b h$. For computing the stem contributions, $P_{\text {stem }}(O)$, we assumed that the likely range of each stem's $D b h$ has a normal distribution with variance one, in addition to its own diameter. So, $P_{\text {stem }}(O)$ can be expressed as

$$
P_{\text {stem }}(O)=\left\{\begin{array}{lc}
1 & 0 \leq d_{s} \leq 0.5 \times D b h \\
N\left(S_{x y}, 1\right) & 0.5 \times D b h<d_{s}
\end{array}\right.
$$

where $d_{s}$ is the horizontal distance from the lidar-estimated tree stem locations $\left(S_{x y}\right)$. 
Other near-ground understory objects include small trees, bushes and boulders, and these also contribute to the occlusion, $P$ u.o. $(O)$. In this study, the "understory" is defined as the height from $0.5 \mathrm{~m}$ to $2 \mathrm{~m}$; the lower and upper bounds (0.5-2 $\mathrm{m}$ ) are selected to be minimized from the ground classification error and counting very low objects that do not affect the visibility or mobility at the height of a person or vehicle. The non-ground lidar points in the understory represent these objects, but are represented sparsely depending on the density of above-ground vegetation.

Considering the size of the laser footprint $(15-20 \mathrm{~cm})$, complete occlusion is assigned to the pixel if there is at least one lidar point inside the range of the pixel plus the approximated laser beam size $(10 \mathrm{~cm})$. The understory object contribution, $P$ u.o. $(O)$, is defined as

$$
P_{u . o .}(O)=\left\{\begin{array}{cc}
1 & 0 \leq d_{u} \leq 0.5 \times \text { pixel_resolution }+10 \mathrm{~cm} \\
0 & \text { elsewhere }
\end{array}\right.
$$

where $d_{u}$ is the horizontal distance from the closest lidar point.

\subsection{Clutter maps}

Having addressed the tree stems and other understory objects, a formal estimate for the probability of obstruction at any 2D location $\left(x_{i}, y_{i}\right)$, $P\left(O \mid X=x_{i}, Y=y_{i}\right)$, over a given forested area of interest can be shown on a 2D map by indexing as a probability from o (open gap) to 1 (complete obstruction) as in the following expression.

$$
P\left(O \mid X=x_{i}, Y=y_{i}\right)=P_{\text {stem }}\left(O \mid x_{i}, y_{i}\right)+P_{\text {u.o. }}\left(O \mid x_{i}, y_{i}\right)
$$

Complete obstruction was given to the pixel where any understory lidar point was found inside the range of the pixel size (here, $50 \mathrm{~cm} \times 50 \mathrm{~cm}$ ) plus the approximated laser beam size $(10 \mathrm{~cm})$ on the map. The lidar points in the search pool were the understory lidar points residing between $0.5 \mathrm{~m}$ and $2 \mathrm{~m}$ from the surface (as described in Section C). And furthermore, the stem contributions to $P(O \mid X, Y)$ are also added to the contributions computed above. The contributed area by a stem is centered at the treetop location in X-Y estimated from the airborne lidar $\left(S_{x y}\right)$, and it is a combination of (1) the size of the diameter obtained from the allometric equation and (2) the likely range assuming a normal distribution. 
As a supplemental information product to the clutter map, a 2D uncertainty map is created to show the probability of uncertainty in the understory space, $P(U \mid X, Y)$, indicating the extent of the lidar undersampling in this layer. This probability reacts to changes in canopy density and structure, and ranges from a value of o (all lidar points reached to this layer) to 1 (no lidar points reached to this layer). This layer is a range of height from the ground surface (o $\mathrm{m}$ ) to the upper bound $(2 \mathrm{~m})$, so all ground points fall in this layer. In between $\mathrm{o}$ and 1 , as defined in equation (4), the probability of uncertainty is a ratio of points in this layer ( $L_{\text {under }}$ ) to all lidar points $\left(L_{\text {all }}\right)$ falling within a fully extended vertical column (ground to highest lidar point recorded) within the $\mathrm{X}-\mathrm{Y}$ range of the pixel size plus the approximate laser beam size (same as the case of searching lidar points for the understory object).

$$
P\left(U \mid X=x_{i}, Y=y_{i}\right)=1-\frac{L_{\text {under }}}{L_{\text {all }}}
$$




\section{Results and Discussion}

To tune the ground point filter, a sensitivity analysis was performed whereby a given parameter's value was incrementally adjusted while holding other parameters constant. Table 2 shows the parameters used in this study with their configurations. Visual inspection relative to the RGB textured terrestrial lidar point cloud was then conducted to examine the effect of the parameter on the classification result. The terrestrial laser scanner has an internal, co-aligned RGB digital camera. The imagery is used to add texture (RGB brightness values) to each point within the terrestrial lidar scan by assigning pixel brightness values to points that fall within a given pixel. Filtering results for the airborne lidar point cloud data were then overlaid with the textured terrestrial $3 \mathrm{D}$ point cloud data using $3 \mathrm{D}$ visualization software to inspect how well a classified set of ground points retains the bare-earth while removing near-ground objects. From the textured point cloud, features such as boulders and vegetation are easily identifiable and used to assess the performance of classification. Visual inspection was also performed using shaded-relief DEMs generated from the classified point set to examine the level of surface detail retained from a given filter run. Results showed that adjustment of the step size parameter in combination with the search space parameter provided nice control on the level of surface roughness retained by the filter. Smaller step sizes resulted in the capture of more surface detail at the cost of increased near-ground clutter whereas a smaller search space resulted in the capture of less surface detail with the benefit of reduced clutter.

Table 2. Parameters and their configurations used in this study.

\begin{tabular}{|c|c|c|c|c|c|c|}
\hline \multicolumn{3}{|c|}{ Bare-earth Surface Modeling } & \multicolumn{3}{c|}{ Individual Tree Segmentation } \\
\hline step size & spike & offset & search space & $\begin{array}{c}\text { search range } \\
(R)\end{array}$ & step size $(\Delta)$ & interval $(T)$ \\
\hline $5 \mathrm{~m}$ & $1 \mathrm{~m}$ & $0.5 \mathrm{~m}$ & extra_fine & $\begin{array}{c}R_{\max }=3 \mathrm{~m} \\
R_{\min }=1 \mathrm{~m}\end{array}$ & $0.5 \mathrm{~m}$ & $0.2 \mathrm{~m}$ \\
\hline
\end{tabular}

In this study, rocks or boulders are not included in the process of estimating the ground surface, which stems from the filter settings implemented for segmentation of the ground points used to model the bare-earth surface. If a decision is made later to treat such objects as part of the estimated ground surface, this can easily be handled through adjustment of the ground point filter settings (refer to Section III); specifically reduction of the step-size in combination with an increased search space to provide a more detailed 
(cluttered) surface representation in the DEM. Additional control on the resultant surface roughness as represented by the DEM can be adjusted through the regularized spline interpolation routine using the smoothness and tension parameters (Mitášová et al. 2005; Hofierka et al. 2007).

In the tree segmentation method developed in this study, the upper bound of the search radius, $R_{\max }$, is the size for which we are certain that the detected points are all treetops (no false alarms), and $3 \mathrm{~m}$ is selected for our study sites. We could choose $R_{\max }$ as large as we want to increase the confidence level on the detected treetops with increased computational cost, but $3 \mathrm{~m}$ was sufficient to account for all the trees in the sites. The lower bound, $R_{\min }$, is the minimum allowable distance between trees, and one meter was the choice in this work. With $R_{\min }=1 \mathrm{~m}$, we assume that separating trees closer than $1 \mathrm{~m}$ is not realistic given the data density and forest complexity, and it would unnecessarily increase the false alarm rate. The average point density in our airborne lidar datasets was about 30 points $/ \mathrm{m}^{2}$, and the average spacing between points was close to $0.3 \mathrm{~m}$. We had larger point gaps that are close to $0.45 \mathrm{~m}$ locally where the area is covered by a single scan line and scan angles are higher. In the range of the search radius, it is not necessary to use too fine a step size, $\Delta$, because the treetop points detected using $R_{i}$ are a subset of them detected using $R_{i-\Delta}$. However, too big a step size creates many fragmented clusters (i.e., parts of a complete tree) and we lose the chance to identify a tree if the tree consists of many clusters before it was identified as a tree in the previous iteration. It is found that $0.5 \mathrm{~m}$ is a moderate choice for the step size in our study by visually examining the results of other step sizes. In the process of region growing to associate points with the tree tops, the interval $T$ was selected as $0.2 \mathrm{~m}$ at the beginning and increased gradually. To save the computational cost, we would want as large an initial $T$ as is feasible, but $0.2 \mathrm{~m}$ was a reasonable choice considering the average spacing between lidar points in our study. The parameters and their final values used in the process are shown in Table 2.

The tree segmentation algorithm proposed in this study was evaluated over the three study sites. The result of combined upper story and mid/understory treetops detected by the algorithm is shown in Figure 5. It is not expected that the tree locations estimated by airborne lidar and measured on the field match perfectly on the horizontal plane because the spatial location of a tree stem at the near-ground level mostly differs from the lidar-estimated treetop to some extent. Manual matching between the 
ground-surveyed trees and lidar-estimated trees is conducted, and the performance of the result was assessed first by counting the total number of trees $(\mathrm{N})$, the omissions $(\mathrm{O})$, the commissions $(\mathrm{C})$, and the total number of errors (E). The Overall Accuracy (OA) is generally computed by counting the number of correctly estimated trees divided by the total number of trees. The Overall Accuracy is the same as the Detection Rate (DR) proposed in (Strimbu and Strimbu, 2015), and in our case, these measures are the same as the Producer Accuracy (PA), which refers to the probability that a tree on the ground is correctly detected as a tree. Another widely used measure in combination with PA is the User Accuracy (UA), which refers to the probability that the detected tree in the map is an actual tree on the ground. These two accuracy measures are used in combination to fully assess classifier performance. To account for both omission and commission, Accuracy Index (AI) is used as introduced in (Strimbu and Strimbu, 2015).

Figure 5. Detected treetop locations on airborne lidar points color-coded by elevation at (a) Hazel, (b) Numbers, and (c) Georgie site (circular area with diameter of $50 \mathrm{~m}$ each). All detected trees are represented as blue circles.

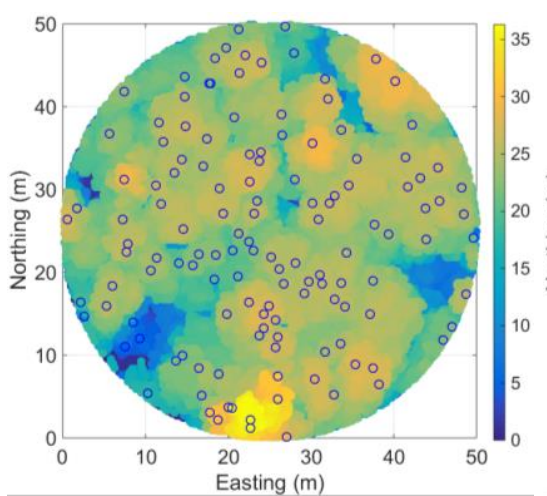

(a)

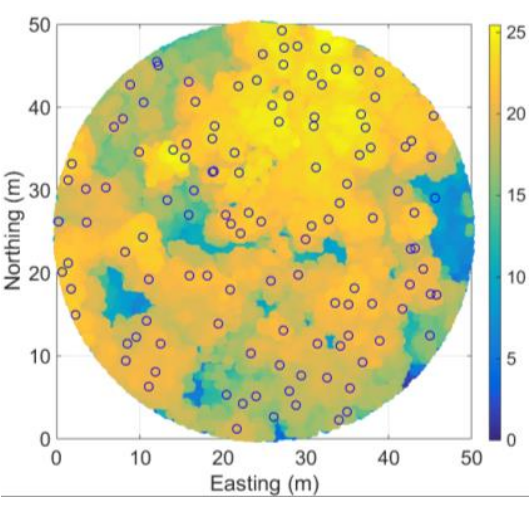

(b)

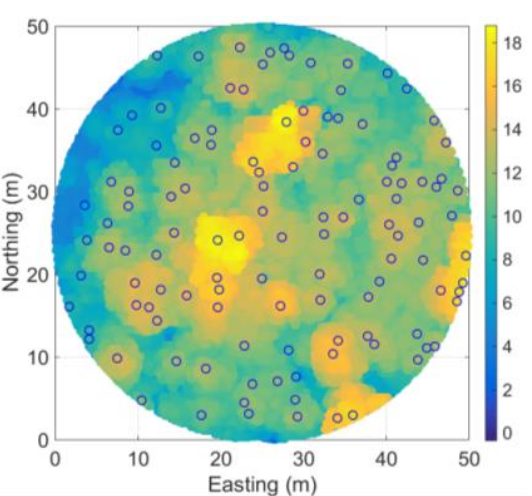

(c)

The accuracy measures of the tree detection result is shown in Table 3. Compared to other measures, UA shows relatively higher accuracies because it only considers the detected trees, and the AI has lower accuracies in all three sites because it accounts for both omission and commission errors. Looking at PA and UA, at Numbers for example, the UA is significantly higher than the PA suggesting that the classifier is not detecting as many trees as represented on the ground (high omission error = lower PA); however, one has good confidence that the detected trees truly are represented as trees on the ground (low commission error $=$ higher UA). Overall, considering the complexity of the study sites, our proposed tree segmentation algorithm showed excellent potential. 
Table 3. Accuracy measures of the individual tree detection results for the study sites

\begin{tabular}{|l|l|l|l|}
\hline Site & Hazel & Numbers & Georgie \\
\hline Total number of trees $(\mathrm{N})$ & 78 & 93 & 83 \\
\hline Total number of trees estimated (T) & 90 & 79 & 75 \\
\hline Omissions (O) & 9 & 21 & 12 \\
\hline Commissions (C) & 21 & 7 & 4 \\
\hline $\begin{array}{l}\text { Total number of errors (E) } \\
(\mathrm{E}=\mathrm{O}+\mathrm{C})\end{array}$ & 30 & 28 & 16 \\
\hline $\begin{array}{l}\text { Producer Accuracy (PA) } \\
(\mathrm{PA}=(\mathrm{N}-\mathrm{O}) / \mathrm{N} \times 100)\end{array}$ & $88.5 \%$ & $77.4 \%$ & $85.5 \%$ \\
\hline $\begin{array}{l}\text { User Accuracy }(\mathrm{UA}) \\
\text { UA }=(\mathrm{N}-\mathrm{O}) / \mathrm{T} \times 100\end{array}$ & $76.7 \%$ & $91.1 \%$ & $94.7 \%$ \\
\hline $\begin{array}{l}\text { Accuracy Index (Al) } \\
\text { Al }=(\mathrm{N}-\mathrm{O}-\mathrm{C}) / \mathrm{N} \times 100\end{array}$ & $61.5 \%$ & $69.9 \%$ & $80.7 \%$ \\
\hline
\end{tabular}

Many different methods have been developed for segmenting individual trees and extracting tree parameters, and efforts have been devoted to compare the existing approaches (Jakubowski et al. 2013; Eysn et al. 2015). However, those comparisons had to be executed in a limited testing environment because it was difficult to consider all the elements that affect the performance (e.g., terrain, tree species, seasonal changes, lidar point density, lidar flight parameters). Our results were directly compared to field measures to assess the validity of the proposed method in the context of the broader problem, which is to estimate near-ground surface clutter. In future work, we can evaluate performance of other tree segmentation algorithms relative to our method both in accuracy and computing efficiency, but in this study, the objective was to develop a framework that can segment the multi-storied trees and estimate the probabilistic contribution of them to near-ground obstruction.

With the combination of the contributions of the tree stems and understory objects, the estimated clutter map in the understory space, $P(O \mid X, Y)$, for each site is created (Figure 6(a)-(c)). As shown in the figure, the probability of occlusion of each pixel is an addition of the contribution of lidar-estimated tree stems to that of understory objects. The lidarestimated stem contribution is considered as a normal distribution, and the mixture of the 2D Gaussian-shaped circles is due to a group of tree stems in a close range. To evaluate the estimated results, we created a clutter map, $P_{\text {truth }}(O \mid X, Y)$, using the terrestrial lidar data for each site and 
considered them as our ground truth (Figure 6(d)-(f)). Unlike the case of searching airborne lidar points in Section III-D, the laser footprint of terrestrial lidar is relatively small, so only the points that fall in the pixel area $(0.1 \mathrm{~m} \times 0.1 \mathrm{~m})$ are considered. Similar to the case of estimation of clutter maps from airborne lidar, complete obstruction (probability $=1$ ) is given to the pixel where any point falls in the pixel area, and no obstruction (probability $=0$ ) is assigned with absence of points. However, to match with the resolution of estimated clutter maps (each pixel of $0.5 \mathrm{~m}$ $\times 0.5 \mathrm{~m}$ ), 25 pixels are merged into one pixel (and those pixel values are averaged for a $0.5 \mathrm{~m} \times 0.5 \mathrm{~m}$ pixel value). Therefore, $P_{\text {truth }}(O \mid X, Y)$ is also a probability map ranging from zero to one with the same pixel size as that of $P(O \mid X, Y)$.

Figure 6. 2D clutter maps (circular area with diameter of $40 \mathrm{~m}$ each) estimated from the airborne lidar data computed for the areas of overlap with the terrestrial lidar surveys, showing the probability of obstruction over the study site (a) Hazel, (b) Numbers, and (c) Georgie. Terrestrial lidar data is used to create the ground truth clutter maps for (d) Hazel, (e) Numbers, and (f) Georgie. Lighter color represents higher possibility of obstruction and darker color represents less obstruction at the specific location. (map

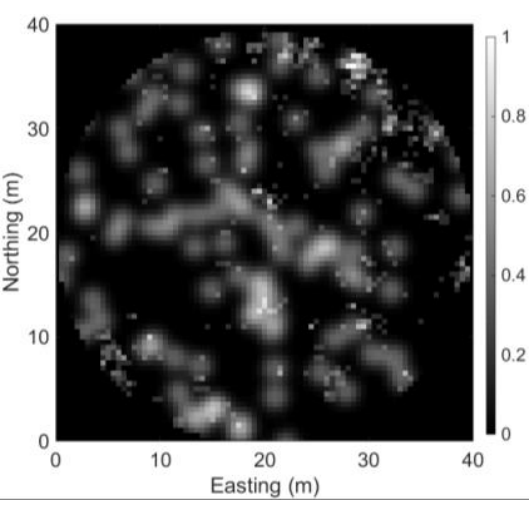

(a)

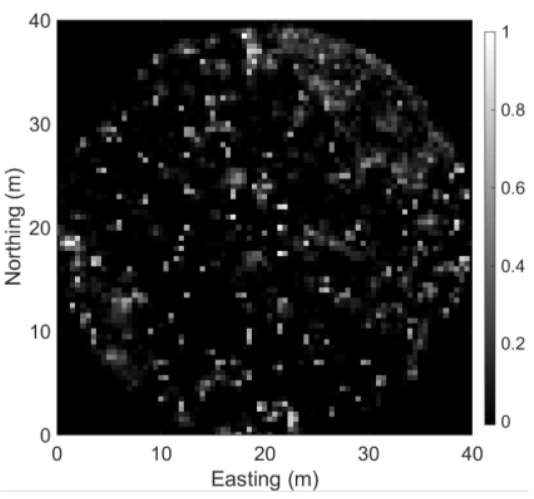

(d)

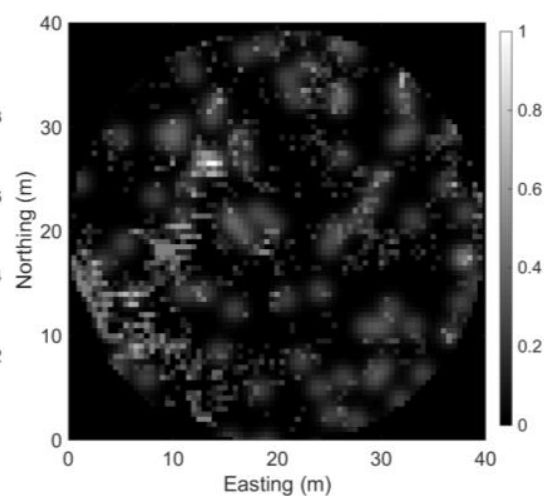

(b)

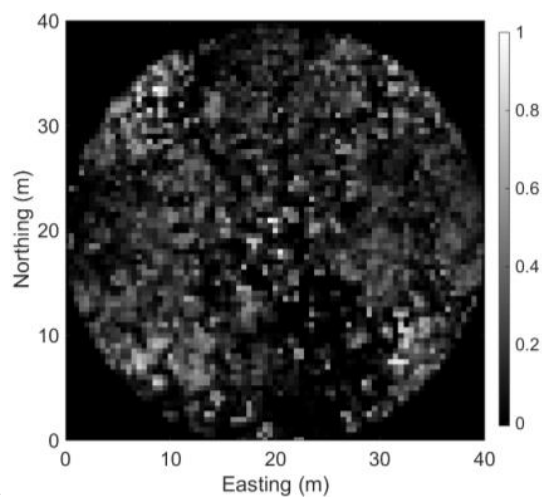

(e)

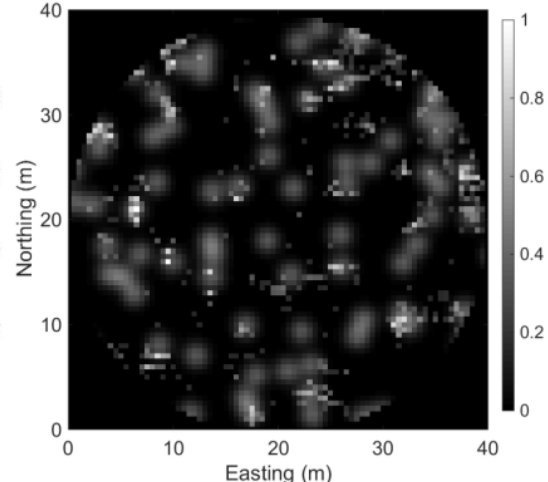

(c)

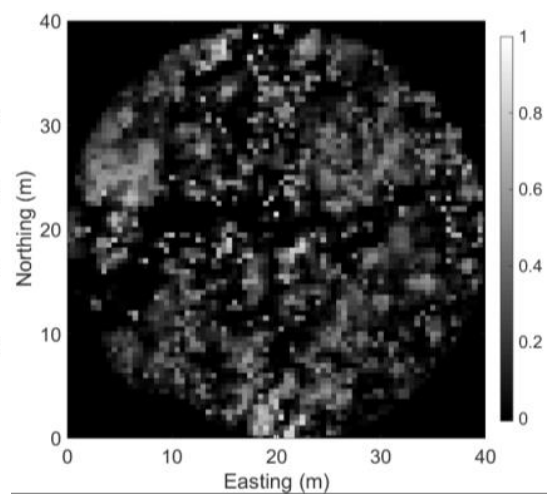

(f) 
Comparing each pixel value between $P(O \mid X, Y)$ and $P_{\text {truth }}(O \mid X, Y)$, the average difference was $0.29,0.35$, and 0.36 , and the root-mean-square error (RMSE) was 0.28, 0.32, and 0.34 for Hazel, Numbers, and Georgie respectively. As probability ranges from zero to one, the worst case (average difference or RMSE $=1$ ) occurs when the estimated occlusion is completely opposite to the ground truth in all pixels. As expected, the site, Hazel, had the best accuracy in the estimation of occlusion because of its least crown closure and lowest stem density. The accuracy in the highest stem density site, Numbers, with relatively shorter trees was obviously lower than the case of Hazel, but interestingly, it was slightly better than the case of Georgie. It seems to be that, compared to the other sites, the airborne lidar could not penetrate the closed canopy cover at Georgie, where the trees are smaller and the stems are thinner, enough to provide information in regards to the near-ground objects.

The clutter maps estimated from the terrestrial lidar point clouds, $P_{\text {truth }}(O \mid X, Y)$, were used as ground truth in our study. However, it is not known how well $P_{\text {truth }}(O \mid X, Y)$ represents the actual environment. We believe that the terrestrial scans captured major structure in the scene, but it would require an almost infinite number of scans to represent the details. Moreover, we assume that the difference of data acquisition times between the terrestrial lidar (in March-May, 2012), field survey (April, 2012) and the airborne lidar (in August, 2012) was another source of discrepancy in the estimations, even though no major changes were recorded in that period in the study sites other than changes due to seasonal progression. Some other sources of discrepancy include (1) registration error between the terrestrial and airborne lidar data and (2) the field-surveyed trees were all greater than $10 \mathrm{~cm}$ in $\mathrm{Dbh}$.

In addition, the probability of uncertainty, $P(U \mid X, Y)$, in the understory space is a supplement to the clutter map to indicate the extent of the lidar undersampling in this layer. This is depicted in Figure 7 using the site Numbers as an example. The clutter map (Figure 7(a)) is shown alongside the uncertainty map (Figure 7(b)). Even though each map provides its own valuable information, it is not always convenient to visually appreciate both the clutter and uncertainty for a specific pixel (or a small local area). A united map that shows both information pieces simultaneously provides another representation of the result even though this is not clear for some locations. The uncertainty map is overlaid on the clutter map with a color scale; red is for higher uncertainty and blue is for lower uncertainty, and the clutter information is shown in shaded relief (Figure $7(\mathrm{c})$ ). 
Figure 7. Result maps at the site of Numbers. (a) A clutter map showing the probability of obstruction, $P(O \mid X, Y)$, over the area of interest (circular area with diameter of $40 \mathrm{~m}$ ) (b) A map showing the probability of uncertainty, $P(U \mid X, Y)$, in the understory space. (c) A 2D united map showing the probabilities of both clutter and uncertainty. The uncertainty is in color scale: more bluish color for less uncertainty and more redish color for more uncetainty. The clutter information is shown as a shaded relief image to produce an appearance of 3D space with lighting from the upper-left corner of the map. The more visually apparent relief indicates higher probability of clutter. (map resolution $=0.5 \mathrm{~m}$ )

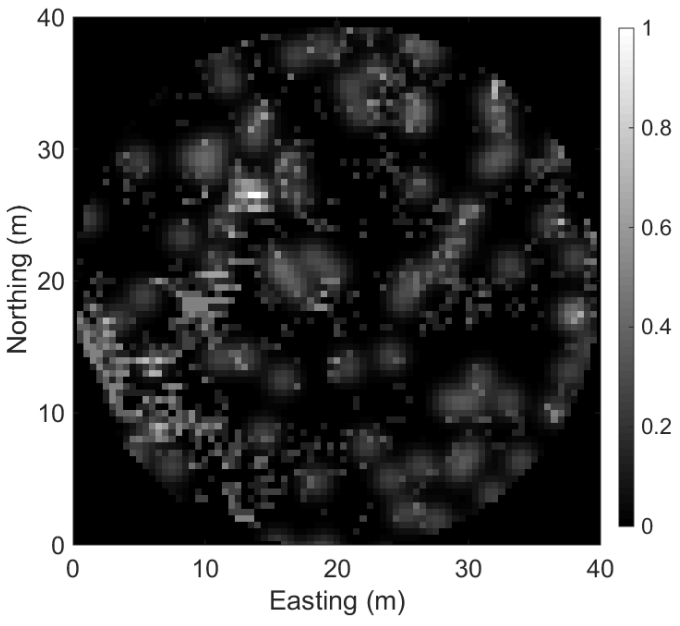

(a)

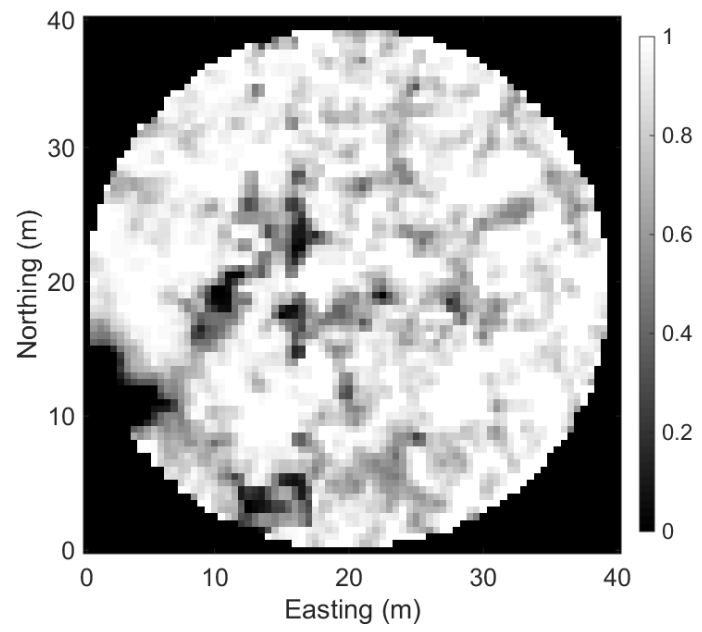

(b)

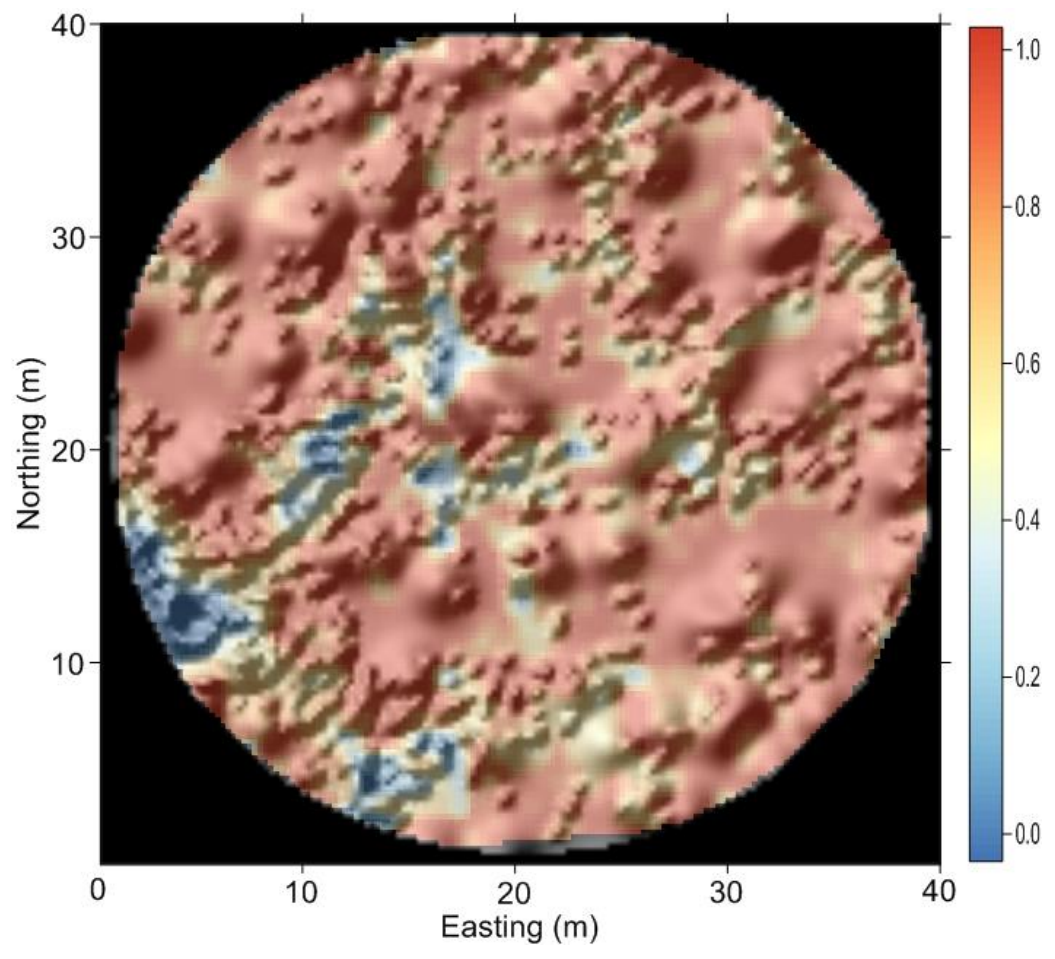

(c) 


\section{Conclusions}

The primary goal of this research was to develop a framework for creating near-ground terrain clutter maps within complex terrain using airborne lidar measurements in a probabilistic manner. The statistically characterized environment with confidence measures in the derived map products shows the probability of occlusion in the understory, $P(O \mid X, Y)$, and also airborne lidar undersampling severity, $P(U \mid X, Y)$, which is an indicator of the uncertainty for the below-canopy region. The estimated obstructions, $P(O \mid X, Y)$, in the map were matched well up to a point with the quasi-ground truth estimated from the terrestrial lidar. The estimated clutter map could be easily lifted up in height up to the top of forest for the estimation of forest structure at each height level, and more generally, it could be used for other applications such as prediction of line-of-sight visibility, photosynthetically active solar radiation, and ground mobility. Furthermore, the essential elements in the map, detected tree stems and near-ground foliage, will complement ongoing efforts to estimate aboveground forest biomass for carbon sequestration and climate modeling studies. The accuracy of detecting individual trees by the proposed algorithm was relatively high considering the complexity and diversity of the study sites. Should an alternative algorithm for upper and mid/lower tree detection be proven better in performance, this method could be integrated here to further improve the model's performance. In addition, the algorithms developed in this study were designed to be compatible with different lidar datasets and different forest types. Future work will deal with investigating the possibility of improvement of the spatial location of a tree stem, which is a major error source in estimating the near-ground clutter because of the horizontal location discrepancy between the tree stem and the lidar-estimated treetop. With denser lidar coverage, lidar points reflected from the tree trunks could be directly used to estimate the tree stem locations, or a parametric relationship between the tree stem location and the tree crown information (e.g., the center of gravity, shape of the crown) well-observed from the air could be further developed. Full-waveform lidar generally provides much more information under the forest canopy, so we expect this approach to yield a better estimation of clutter in the lower level of forest structure. 


\section{References}

Awrangjeb, M., and C. S. Fraser. 2014. "Automatic segmentation of raw lidar data for extraction of building roofs," Remote Sensing, vol. 6(5), pp. 3716-3751.

Axelsson, P. 2000. "DEM generation from laser scanner data using adaptive TIN models," International Archives of Photogrammetry and Remote Sensing, vol. 33 .

Besl, P. J., and N. D. McKay. 1992. "A method for registration of 3-D shapes," IEEE Transactions on Pattern Analysis and Machine Intelligence, vol. 14(2), pp. 239256.

Booth, A. M., J. J. Roering, and A. W. Rempel. 2013. "Topographic signatures and a general transport law for deep-seated landslides in a landscape evolution model," Journal of Geophysical Research: Earth Surface, vol. 118(2), pp. 603-624.

Bucksch, A., R. Lindenbergh, M. Z. Abd Rahman, and M. Menenti. 2014. "Breast height diameter estimation from high-density airborne lidar data," Geoscience and Remote Sensing Letters, vol. 11, pp. 1056-1060.

Chen, Q., P. Gong, D. Baldocci, and Y.Q. Tian. 2007. "Estimating basal area and stem volume for individual trees from lidar data," Photogrammetric Engineering and Remote Sensing, vol. 73(12), pp. 1355-1365.

Eysn, L., M. Hollaus, E. Lindberg, F. Berger, J. Monnet, M. Dalponte, M. Kobal, M. Pellegrini, E. Lingua, D. Mongus, and N. Pfeifer. 2015. "A benchmark of lidarbased single tree detection methods using heterogeneous forest data from the Alpine space," Forests, vol. 6, pp. 1721-1747.

Fernandez-Diaz, J. C., W. E. Carter, R. L. Shrestha, and C. L. Glennie. 2014. "Now you see it... now you don't: understanding airborne mapping lidar collection and data product generation for archaeological research in Mesoamerica," Remote Sensing, vol. 6(10), pp. 9951-10001.

Habib, A., M. Ghanma, M. Morgan, and R. l-Ruzouq. 2005. "Photogrammetric and lidar data registration using linear features," Photogrammetric Engineering \& Remote Sensing, vol. 71(6), pp. 699-707.

Hare, T., M. Masson, and B. Russell. 2014. "High-density lidar mapping of the ancient city of Mayapan," Remote Sensing, vol. 6(9), pp. 9064-9085.

Henning, J. G., and P. J. Radtke. 2006. "Detailed stem measurements of standing trees from ground-based scanning lidar." Forest Science, 52.1, pp. 67-80.

Hofierka, J., T. Cebecauer, and M. Š́ri. 2007. "Optimisation of interpolation parameters using cross-validation," Digital Terrain Modelling. Springer Berlin Heidelberg, pp. 67-82.

Isenburg, M. 2015. "LAS Tools Ground Point Filter,” www.cs.unc.edu/ isenburg/lastools/. 
Jakubowski, M. K., W. Li, Q. Guo, and M. Kelly. 2013. "Delineating individual trees from lidar data: a comparison of vector- and raster-based segmentation approaches," Remote Sensing, vol. 5, pp. 4163-4186.

Johnson, A. E., and M. Hebert. 1999. "Using spin images for efficient object recognition in cluttered 3D scenes," IEEE Transactions on Pattern Analysis and Machine Intelligence, vol. 21(5), pp. 433-449.

Khosravipour, A., A. K. Skidmore, J. Wang, M. Isenburg, and K. Khoshelham. 2015. "Effect of slope on treetop detection using a lidar canopy height model," ISPRS Journal of Photogrammetry and Remote Sensing, vol. 104, pp. 44-52.

Lee, H. 2008. "3D feature extraction and geometric mappings for improved parameter estimation in forested terrain using airborne lidar data," Ph.D. dissertation, University of Florida, Gainesville, FL, USA.

Lee, H., K. C. Slatton, W. P. Cropper, and B. E. Roth. 2009. "Prediction of forest canopy light interception using three-dimensional airborne lidar data," International Journal of Remote Sensing, vol. 30(1), pp. 189-207.

Lee, H., K. C. Slatton, B. E. Roth, and W. P. Cropper. 2010. "Adaptive clustering airborne lidar data to segment individual tree crowns," International Journal of Remote Sensing, vol. 31(1), pp. 117-139.

Lee, H., S. B. Blundell, M. J. Starek, and J. G. Harris. 2013. "Airborne lidar point cloudbased below-canopy line-of-sight visibility estimator," Journal of Applied Remote Sensing, vol. 7(1), 073510.

Lefsky, M., W. Cohen, G. Parker, and D. Harding. 2002. "Lidar remote sensing for ecosystem studies," Bioscience, vol. 52(1), pp. 19-30.

Liu, P. W., H. Lee, J. Judge, W. C. Wright, and K. C. Slatton. 2011. "Prediction of L-band signal attenuation in forests using $3 \mathrm{D}$ vegetation structure from airborne lidar," ISPRS Journal of Photogrammetry and Remote Sensing, vol. 66, pp. 642-651.

Lu, W., K. P. Murphy, J. J. Little, A. Sheffer, and H. Fu. 2009. “A hybrid conditional random field for estimating the underlying ground surface from airborne lidar data," IEEE Transactions on Geoscience and Remote Sensing, vol. 47(8), pp. 2913-2922.

Lu, Z., I. Jungho, and L. Quackenbush. 2011. "A volumetric approach to population estimation using lidar remote sensing," Photogrammetric Engineering and Remote Sensing, vol. 77(1), pp. 1145-1156.

Maltamo, M., E. Nasset, and J. Vauhkonen, Eds. 2014. Forestry Applications of Airborne Laser Scanning. New York, NY, USA: Springer.

Mitášová, H., and L. Mitáš. 1993. "Interpolation by regularized spline with tension: I. Theory and implementation," Mathematical Geology, vol. 25.6, pp. 641-655.

Mitášová, H., L. Mitáš, and R. S. Harmon. 2005. "Simultaneous spline approximation and topographic analysis for lidar elevation data in open-source GIS," IEEE Geoscience and Remote Sensing Letters, vol. 2(4), pp. 375-379. 
Nissen, E., A. K. Krishnan, J. R. Arrowsmith, and S. Saripalli. 2012. "Three-dimensional surface displacements and rotations from differencing pre-and post-earthquake lidar point clouds," Geophysical Research Letters, vol. 39.16.

Oskin, M. E., J. R. Arrowsmith, A. H. Corona, A. J. Elliot, J. M. Fletcher, E. J. Fielding, P. O. Gold, J. G. Garcia, K. W. Hudnut, J. Lie-Zeng, and O. J. Teran. 2012. "Nearfield deformation from the El Mayor-Cucapah earthquake revealed by differential lidar," Science, vol. 335(6069), pp. 702-705.

Palminteri, S., G. V. Powell, G. P. Asner, and C. A. Peres. 2012. "Lidar measurements of canopy structure predict spatial distribution of a tropical mature forest primate," Remote Sensing of Environment, vol. 127, pp. 98-105.

Polat, N., and M. Uysal. 2015. "Investigating performance of airborne lidar data filtering algorithms for DTM generation," Measurement, vol. 63, pp. 61-68.

Popescu, S.C. 2007. "Estimating biomass of individual pine trees using airborne lidar," Biomass Bioenergy, vol. 31(9), pp. 646-655.

Strimbu, V. F., and B. M. Strimbu. 2015. "A graph-based segmentation algorithm for tree crown extraction using airborne lidar data," ISPRS Journal of Photogrammetry and Remote Sensing, vol. 104, pp. 30-43.

Vega, C., S. Durrieu, J. Morel, and T. Allouis. 2012. "A sequential iterative dual-filter for lidar terrain modeling optimized for complex forested environments," Computers \& Geosciences, vol. 44, pp. 31-41.

Vosselman, G., and H. G. Maas. 2010. Airborne and Terrestrial Laser Scanning, Dunbeath, Scotland: Whittles.

Wilson, J. P. 2012. “Digital terrain modeling,” Geomorphology, vol. 137, pp. 107-121.

Wright, W. C., P. W. Liu, K. C. Slatton, R. L. Shrestha, W. E. Carter, H. Lee. 2008. "Predicting L-band microwave attenuation through forest canopy using directional structuring elements and airborne lidar," Proc. IEEE International Geoscience and Remote Sensing Symposium (IGARSS), Boston, MA, USA, vol. 3, pp. 1ll-688 - lll-691.

Yang, B., Y. Zang, Z. Dong, and R. Huang. 2015. "An automated method to register airborne and terrestrial laser scanning point clouds," ISPRS Journal of Photogrammetry and Remote Sensing, vol. 109, pp. 62-76.

Zielke, O., Y. Klinger, and J. R. Arrowsmith. 2015. "Fault slip and earthquake recurrence along strike-slip faults contributions of high-resolution geomorphic data," Tectonophysics, vol. 638, pp. 43-62. 


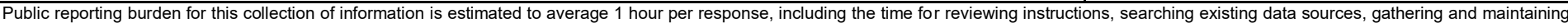

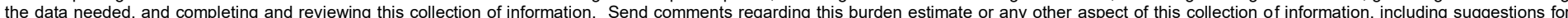

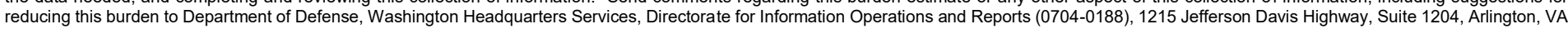

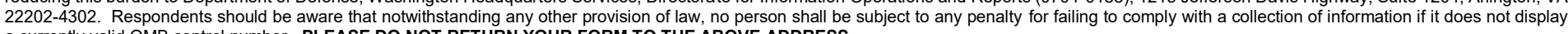
a currently valid OMB control number. PLEASE DO NOT RETURN YOUR FORM TO THE ABOVE ADDRESS.
1. REPORT DATE (DD-MM-YYYY) 2. REPORT TYPE
December 2019 Final
3. DATES COVERED (From - To)

\section{TITLE AND SUBTITLE}

Estimation of 2D Clutter Maps in Complex Under-Canopy Environments from Airborne Discrete-Return Lidar

\section{5a. CONTRACT NUMBER}

5b. GRANT NUMBER

5c. PROGRAM ELEMENT NUMBER

\section{AUTHOR(S)}

Heezin Lee, Michael J. Starek, S. Bruce Blundell, Michael Schwind, Christopher Gard, and Harry Puffenberger

\section{5d. PROJECT NUMBER}

5e. TASK NUMBER

\section{5f. WORK UNIT NUMBER}

\section{PERFORMING ORGANIZATION NAME(S) AND ADDRESS(ES) (see reverse)}

8. PERFORMING ORGANIZATION REPORT NUMBER

ERDC/GRL MP-19-2

9. SPONSORING / MONITORING AGENCY NAME(S) AND ADDRESS(ES)

10. SPONSOR/MONITOR'S ACRONYM(S)

U.S. Army Corps of Engineers

Washington, DC 20314-1000

11. SPONSOR/MONITOR'S REPORT NUMBER(S)

\section{DISTRIBUTION / AVAILABILITY STATEMENT}

Approved for public release; distribution is unlimited.

\section{SUPPLEMENTARY NOTES}

GATE/ULM 11L025

IEEE Journal of Selected Topics in Applied Earth Observations and Remote Sensing, Vol. 9, No. 12, December 2016

\section{ABSTRACT}

Detection of near-ground objects occluded by above-ground vegetation from airborne lidar measurements remains challenging. Our hypothesis is that the probability of obstruction due to objects above ground at any location in the forest environment can be reasonably characterized solely from airborne lidar data. The essence of our approach is to develop a data-driven learning scheme that creates highresolution $2 \mathrm{D}$ probability maps for obstruction in the under-canopy environment. These maps contain information about the probabilities of obstruction (clutter map) and lidar undersampling (uncertainty map) in the near-ground space. Airborne and terrestrial lidar data and field survey data collected within the forested, mountainous environment of Shenandoah National Park, Virginia USA are utilized to test and evaluate the proposed approach in this work. A newly developed individual tree detection algorithm is implemented to estimate undersampled stem contributions to the probability of obstruction. Results show the effectiveness of the tree detection algorithm with an accuracy index of between $61.5 \%$ and $80.7 \%$ (tested using field surveys). The estimated clutter maps are compared to the maps created from terrestrial scans (i.e., ground truth) and the results show the root-mean-square error of $0.28,0.32$, and 0.34 at three study sites. The overall framework in deriving near-ground clutter and uncertainty maps from airborne lidar data would be useful information for prediction of line-of-sight visibility, mobility and above-ground forest biomass.

\section{SUBJECT TERMS}

Forestry, lidar, terrain modeling, tree segmentation

\section{SECURITY CLASSIFICATION OF:}

\section{a. REPORT}

Unclassified

\section{b. ABSTRACT \\ Unclassified}

\section{c. THIS PAGE}

Unclassified
17. LIMITATION OF ABSTRACT

SAR
18. NUMBER OF PAGES

35 19a. NAME OF RESPONSIBLE PERSON

19b. TELEPHONE NUMBER (include area code) 


\section{PERFORMING ORGANIZATION NAME(S) AND ADDRESS(ES) (concluded)}

National Center for Airborne Laser Mapping

Department of Earth and Planetary Science

University of California at Berkeley

Berkeley, CA 94720

School of Engineering and Computing Sciences

Texas A\&M University - Corpus Christi

Corpus Christi, TX 78412

U.S. Army Engineer Research and Development Center Geospatial Research Laboratory

7701 Telegraph Road

Alexandria, VA 22315 